\title{
Diseases Burden of Chronic Obstructive Pulmonary Disease (COPD) Attributable to Ground-Level Ozone in Thailand: Estimates Based on Surface Monitoring Measurements Data
}

\author{
Chayut Pinichka ${ }^{1}$, Kanitta Bundhamcharoen ${ }^{1} \&$ Kenji Shibuya ${ }^{2}$ \\ ${ }^{1}$ International Health Policy Program, Ministry of Public Health, Nonthaburi 11000, Thailand \\ ${ }^{2}$ Department of Global Health Policy Graduate School of Medicine, The University of Tokyo, Japan \\ Correspondence: Kanitta Bundhamcharoen, International Health Policy Program, Ministry of Public Health, \\ Nonthaburi 11000, Thailand. Tel: 66-2590-2383; Fax: 66-2590-2380. E-mail: kanitta@ihpp.thaigov.net; \\ chayut@ihpp.thaigov.net
}

Received: February 1, $2015 \quad$ Accepted: April 3, $2015 \quad$ Online Published: May 15, 2015
doi:10.5539/gjhs.v8n1p1
URL: http://dx.doi.org/10.5539/gjhs.v8n1p1

\begin{abstract}
Background: Ambient ozone $\left(\mathrm{O}_{3}\right)$ pollution has increased globally since preindustrial times. At present, $\mathrm{O}_{3}$ is one of the major air pollution concerns in Thailand, and is associated with health impacts such as chronic obstructive pulmonary disease (COPD). The objective of our study is to estimate the burden of disease attributed to $\mathrm{O}_{3}$ in 2009 in Thailand based on empirical evidence.
\end{abstract}

Methods: We estimated disability-adjusted life years (DALYs) attributable to $\mathrm{O}_{3}$ using the comparative risk assessment framework in the Global Burden of Diseases (GBD) study. We quantified the population attributable fraction (PAF), integrated from Geographic Information Systems (GIS)-based spatial interpolation, the population distribution of exposure, and the exposure-response coefficient to spatially characterize exposure to ambient $\mathrm{O}_{3}$ pollution on a national scale. Exposure distribution was derived from GIS-based spatial interpolation $\mathrm{O}_{3}$ exposure model using Pollution Control Department Thailand (PCD) surface air pollution monitor network sources. Relative risk (RR) and population attributable fraction (PAF) were determined using health impact function estimates for $\mathrm{O}_{3}$.

Result: PAF (\%) of COPD attributable to $\mathrm{O}_{3}$ were determined by region: at approximately, Northern $=2.1$, Northeastern $=7.1$, Central $=9.6$, Eastern $=1.75$, Western $=1.47$ and Southern $=1.74$. The total COPD burden attributable to $\mathrm{O}_{3}$ for Thailand in 2009 was 61,577 DALYs. Approximately $0.6 \%$ of the total DALYs in Thailand is male: 48,480 DALYs; and female: 13,097 DALYs.

Conclusion: This study provides the first empirical evidence on the health burden (DALYs) attributable to $\mathrm{O}_{3}$ pollution in Thailand. Varying across regions, the disease burden attributable to $\mathrm{O}_{3}$ was $0.6 \%$ of the total national burden in 2009. Better empirical data on local specific sites, e.g. urban and rural areas, alternative exposure assessment, e.g. land use regression (LUR), and a local concentration-response coefficient are required for future studies in Thailand.

Keywords: ambient ozone pollution, population attributable fraction, geographic information system, spatial interpolation, burden of disease, disability adjusted life years

\section{Introduction}

Ground-level ozone or ambient ozone pollution $\left(\mathrm{O}_{3}\right)$ is one of the major air pollution concerns at both national and global levels, which are associated with health impacts, such as premature mortality due to respiratory infection (Huang, Dominici, \& Bell, 2005; Ito, Thurston, \& Silverman, 2007; M. Jerrett et al., 2009). The Global Burden of Diseases study 2010 (GBD, 2010) (WHO, 2011) estimated that the burden attributed to $\mathrm{O}_{3}$ exposure distributions accounted for 0.2 million or $0.1 \%$ of global DALYs in 2010, approximately $6.3 \%$ larger than the burden in 1990 (Lim et al., 2012). A study by Anenberg et al (Anenberg, Horowitz, Tong, \& West, 2010) using the chemistry transport model, estimated global annual respiratory mortality of $0.7 \pm 0.3$ million $(6.3 \pm 3.0$ million years of life lost), or $1.1 \% \pm 0.5 \%$ of all respiratory mortalities were associated with $\mathrm{O}_{3}$ pollution. In addition, almost $80 \%$ of the total global $\mathrm{O}_{3}$ pollution impact in this study occurred in Asia. Since $1997, \mathrm{O}_{3}$ has 
dramatically exceeded the standard level in many areas of Thailand because of rapidly expanding cities, increasing population density, increasing trend in the number of fossil fuel vehicles and electricity generation (Ruchirawat, Settachan, Navasumrit, Tuntawiroon, \& Autrup, 2007; Thanh \& Lefevre, 2000). $\mathrm{O}_{3}$ can be formed in mega cities and carried toward rural areas and distributed across the country via atmospheric transport pathways, therefore, it is necessary to quantify the health burden of $\mathrm{O}_{3}$ pollution at the national level.

Global estimates of ozone by the powerful chemistry transport model may be under or over-estimating the results because it does not use national level empirical data at the local level. Thailand has used $\mathrm{O}_{3}$ surface monitored measurements from the Pollution Control Department in recent years, which when used with data from geographic information system (GIS), can improve simulated $\mathrm{O}_{3}$ distribution at a specific level. GIS is a well-known program and has been used to estimate the exposure distribution in many environmental epidemiology studies including $\mathrm{O}_{3}$ pollution exposure (Moral García et al., 2010; Hunova, 2011; Nuckols \& Lars Jarup, 2004; Verónica, 2013). To estimate the health burden attributed to $\mathrm{O}_{3}$ in Thailand, it is necessary to develop an accurate prediction of the distribution of $\mathrm{O}_{3}$ exposure values at non-measurement locations with the empirical data available at the local level.

Our main objective was to estimate the attributable burden of disease due to $\mathrm{O}_{3}$ exposure in Thailand using the spatial interpolation of $\mathrm{O}_{3}$ concentrations, health impact function and calculated disability-adjusted life years (DALYs), which are a composite metric that measures both deaths and disabilities, combined with the comparative risk assessment method (Lim et al., 2012; Murray, 1994).

\section{Method}

\subsection{Overall Approach to Estimating Burden Attributable to $\mathrm{O}_{3}$}

GBD uses the disability-adjusted life-year (DALY) as developed by the Burden of Disease workgroup at the World Health Organization (WHO) to quantify the burden of disease. DALY is the sum of the years of life lived with a disability (YLD) and years of life lost (YLL). Our methods are based on the GBD 2010 comparative risk assessment (Lim et al., 2012). We use an integrated method that combines exposure assessment based on surface monitoring measurements and comparative risk assessment (CRA) to quantify the burden of disease attributed to ambient $\mathrm{O}_{3}$ pollution as shown in Table 1. The comparative risk assessment method used to calculate the attributable burden due to $\mathrm{O}_{3}$ in this study is based on epidemiological evidence for $\mathrm{O}_{3}$ exposure. Exposure-response relationships for $\mathrm{O}_{3}$ are derived from epidemiological studies in GBD 2010, to calculate attributable fractions, and are then multiplied by disease burden, and expressed in DALYs attributable to $\mathrm{O}_{3}$ (WHO, 2004).

Essentially, the estimation of the burden attributable to $\mathrm{O}_{3}$ consists of three main steps: (1) measuring the total burden of disease associated with the risk factor at the population level, (2) estimating the population attributable fraction (PAF), and finally (3) applying the PAF to the total burden of disease.

Table 1. Risk factors included, exposure variables, theoretical-minimum-risk exposure distributions, and outcomes affected

\begin{tabular}{|c|c|c|c|c|c|c|c|}
\hline $\begin{array}{l}\text { Air } \\
\text { pollution } \\
\text { type }\end{array}$ & $\begin{array}{l}\text { Exposure } \\
\text { definition }\end{array}$ & Outcomes & Subgroup & $\begin{array}{lr}\text { Main } & \text { data } \\
\text { sources } & \text { for } \\
\text { exposure } & \end{array}$ & $\begin{array}{l}\text { Exposure } \\
\text { estimation } \\
\text { method }\end{array}$ & $\begin{array}{l}\text { Theoretical } \\
\text { minimum-risk } \\
\text { exposure } \\
\text { distribution }\end{array}$ & $\begin{array}{l}\text { Source of } \\
\text { relative } \\
\text { risks }\end{array}$ \\
\hline $\begin{array}{l}\text { Ambient } \\
\text { ozone } \\
\text { pollution }\end{array}$ & $\begin{array}{l}\text { Ambient } \\
\text { concentrations } \\
\text { of ozone in air, } \\
\text { measured in } \\
\text { parts per } \\
\text { billion }\end{array}$ & COPD & $\begin{array}{l}\text { Age } \geq 25 \\
\text { years }\end{array}$ & $\begin{array}{l}\text { Surface } \\
\text { monitor } \\
\text { measure-ments }\end{array}$ & $\begin{array}{l}\text { Surface } \\
\text { monitor } \\
\text { measurements } \\
\text { and GIS } \\
\text { interpolation }\end{array}$ & $\begin{array}{l}33.3-41.9 \text { parts } \\
\text { per billion }\end{array}$ & $\begin{array}{l}\text { Jerrett and } \\
\text { Colleague } \\
\text { (M. Jerrett } \\
\text { et al., } \\
\text { 2009) }\end{array}$ \\
\hline
\end{tabular}

\subsection{Data Sources}

\subsection{1 $\mathrm{O}_{3}$ Exposure}

The most important part of the $\mathrm{O}_{3}$ concentration estimation is the extrapolation of pollutant levels at different spatial locations based on empirical data from air quality monitoring stations in Thailand. The monitoring 
stations are located in six-regions (Northern, Northeastern, Eastern, Western, Central, and Southern) and monitor particulate matter (PM 10), fine particles ( $\mathrm{PM} 2.5$ ), $\mathrm{CO}, \mathrm{NO}_{2}, \mathrm{SO}_{2}$, and ground-level ozone. The stations are operated by the Thailand Pollution Control Department (PCD), which has been monitoring $\mathrm{O}_{3}$ since 1992 through the Thailand air quality monitoring network. The network consists of 55 continuous monitoring stations in 23 provinces, and $52 \mathrm{O}_{3}$ monitor stations across the country (Pollution Control Department, 2007). Figure 1 illustrates the location of these air quality monitoring stations and regions, and Table 2 shows the number of $\mathrm{O}_{3}$ surface-monitoring stations by regions in Thailand.

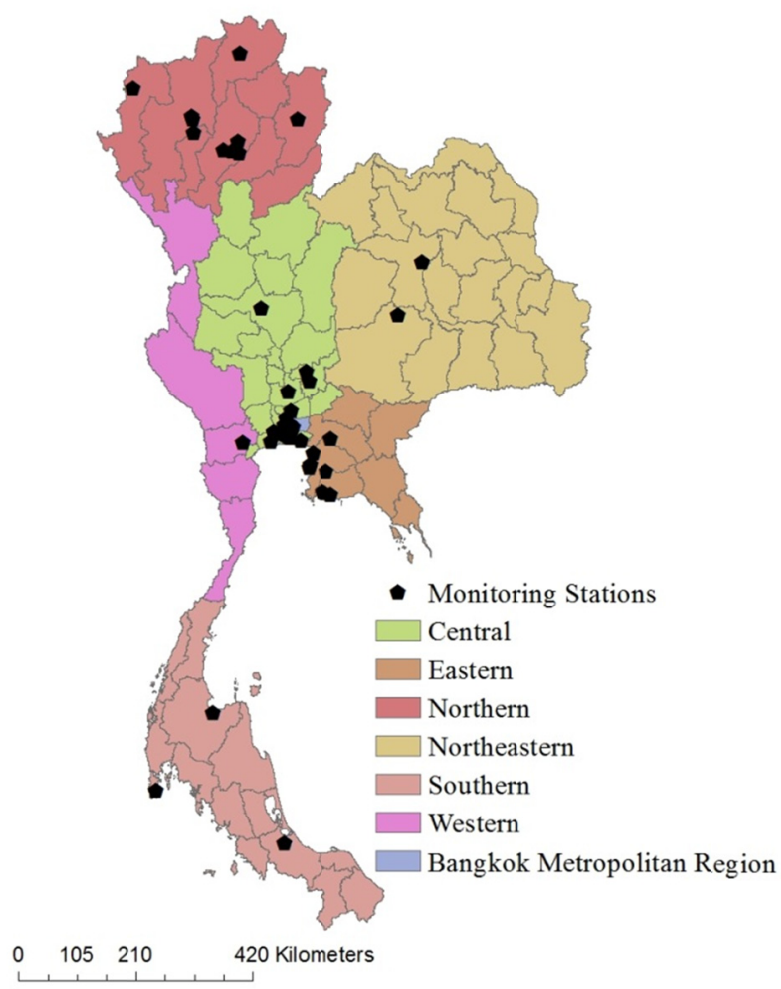

Figure 1. Area of the study and location of surface monitoring stations network

Table 2. Number of $\mathrm{O}_{3}$ surface monitor stations and regional categorization in Thailand

\begin{tabular}{ll}
\hline Locations & Number of stations \\
\hline Central (including Bangkok Metropolitan Area) & 28 \\
Northern & 10 \\
Northeastern & 2 \\
Eastern & 8 \\
Western & 1 \\
Southern & 3 \\
\hline Total & 52 \\
\hline
\end{tabular}

Note. source: (Pollution Control Department, 2007).

Geo-statistics and spatial exposure modeling techniques were applied to air pollution exposure assessment in a number of environmental-health studies (Hunova, 2011; M. Jerrett et al., 2013; Thepanondh \& Toruksa, 2011). The spatial modeling technique estimates the unknown value of an un-observed area within the area covered by using an existing known value observation. GIS allowed us to study and analyze spatial distributions of $\mathrm{O}_{3}$ pollution on a national level based on empirical data. Because of these advantages, GIS can also be a powerful tool to show spatial distribution of the exposure. Without a GIS assessment, exposure distribution analysis of 
national air pollution data would be difficult to obtain.

Inverse distance weighting (IDW) is a deterministic interpolation method and based on the nonlinear interpolation technique that uses a weighted average of the attribute values from nearby known value data to estimate the value of that attribute at unknown data locations. Moreover, IDW showed good results for assessment and monitoring of ambient air quality parameters (Dilip Kumar Jha, Sabesan, Anup Das, Vinithkumar, \& Kirubagaran, 2011).

The model formula of IDW interpolation is given by;

$$
Z_{j}=\frac{\sum_{i}\left(\frac{z_{i}}{d_{i j}^{n}}\right)}{\sum_{i}\left(\frac{1}{d_{i j}^{n}}\right)}
$$

$\mathrm{Z}_{\mathrm{j}}$ is the estimated of $\mathrm{O}_{3}$ concentrations value at location $\mathrm{j}$;

$\mathrm{Z}_{\mathrm{i}}$ is the measured of $\mathrm{O}_{3}$ concentrations value at location $\mathrm{i}$;

$\mathrm{d}_{\mathrm{ij}}$ is the distance from measured value at location $\mathrm{i}$ to the estimated value at location $\mathrm{j}$;

$\mathrm{n}$ is the number of $\mathrm{O}_{3}$ concentrations measured value points used for interpolation.

In addition to the IDW method, several studies used the Kriging method to evaluate $\mathrm{O}_{3}$ exposure (Denby et al., 2010; Gorai, Tuluri, \& Tchounwou, 2014; Kethireddy, Tchounwou, Ahmad, Yerramilli, \& Young, 2014; Roberts, Voss, \& Knight, 2014). Kriging weights the distance between measured locations based on its spatial correlation to produce variograms and a covariance factor for predicting the unknown locations (Wong, Yuan, \& Perlin, 2004). In this study, cross-validation analysis was used to evaluate the performance of the spatial interpolation techniques and the uncertainty of the maps (Janssen, Dumont, Fierens, \& Mensink, 2008); we used Pearson correlation ( $\mathrm{r}$ ) between the measured values at the monitoring stations and the model predictions. We assessed the model performance by statistical performance indicators comparing the Root Mean Squared Error (RMSE) and Mean Absolute Error (MAE). The equation is given by;

$$
\begin{aligned}
M S E & =\sqrt{\frac{1}{N} \sum_{i=1}^{N}\left(X_{i}-X^{\prime}{ }_{i}\right)^{2}} \\
M A E & =\frac{1}{N} \sum_{i=1}^{N}\left|X_{i}-X^{\prime}{ }_{i}\right|
\end{aligned}
$$

Where, $X_{i}, X_{i}^{\prime}$ and $N$ are measured, estimated and number of variables.

\subsubsection{Relative Risks and Population Attributable Fraction}

The population attributable fraction (PAF) has long been used to estimate the proportion reduction of burden that can be attributed to specified risk factors (Levin, 1953; Rockhill, Newman, \& Weinberg, 1998) . If these risk factors were eliminated, it can be concluded that the burden would be reduced from these risk factors. Generally, an exposure-based approach to determine the PAF attributed to $\mathrm{O}_{3}$ requires three components of data: the exposure of the $\mathrm{O}_{3}$, the population of exposure (Pe), and the exposure-response relationships or Relative Risk (RR). We calculated the health impact function for $\mathrm{O}_{3}$ based on a log-linear relationship between relative risk (RR) and concentrations defined by an epidemiological study (M. Jerrett et al., 2009). We used relative risk from this study because it is the first study that showed significant $\mathrm{O}_{3}$ long-term health impact. In addition, the GBD 2010 only used RR from this study for their estimations. We assumed that the background $\mathrm{O}_{3}$ concentrations, the relationship between $\mathrm{O}_{3}$ and health impact in Thailand, are on the same scale as the GBD 2010. The health impact function was evaluated based on the relationship between relative risk (RR) and the change in $\mathrm{O}_{3}$ concentrations, defined as follows;

$$
R R=\exp ^{\beta\left(x-x_{0}\right)}
$$

Where $\beta$ is the concentration-response coefficient (CR), which is the slope of the log-linear between $\mathrm{O}_{3}$ concentrations and mortality, and $\mathrm{x}-\mathrm{x}_{0}$ or $\Delta \mathrm{x}$ is the concentration change from baseline conditions $\left(\mathrm{x}_{0}\right)$, defined as follows:

$\mathrm{X}=$ Average annual 1-hours daily maximum $\mathrm{O}_{3}$ concentrations in 1997-2009 (ppb)

$\mathrm{X}_{0}=$ Theoretical minimum or background concentrations (ppb)

We calculated the burden of disease attributable to ambient $\mathrm{O}_{3}$ pollution by multiplying the total disease burden and the PAF which was determined by equation 5 (Murray, Ezzati, Lopez, Rodgers, \& Vander Hoorn, 2003), where $\mathrm{Pe}$ is the population distribution of the exposure and RR is the relative risk. 


$$
P A F=\frac{P e(R R-1)}{P e(R R-1)+1}
$$

The exposed population may itself be divided into multiple categories based on level or length of exposure each with its own relative risk. With multiple (n) exposure categories, the PAF is given by the following generalized form(Murray et al., 2003) :

$$
P A F=\frac{\sum_{i=1}^{n} P e_{i}\left(R R_{i}-1\right)}{\sum_{i=1}^{n} P e_{i}\left(R R_{i}-1\right)+1}
$$

$\mathrm{PAF}=$ Proportion of disease burden attributable to $\mathrm{O}_{3}$.

$\mathrm{Pe}_{\mathrm{i}}=$ Proportion estimates of the population that's exposed to $\mathrm{O}_{3}$ by grid $\mathrm{i}$.

$\mathrm{RR}_{\mathrm{i}}=$ Relative risk (magnitude of the association between $\mathrm{O}_{3}$ and disease) by grid $\mathrm{i}$.

We used relative risk of chronic obstructive pulmonary disease (COPD) from Jerrett et al. (M. Jerrett et al., 2009). The population data used in this study was obtained from the 2000 Gridded Population of the World, Version 3 (GPWv3) generated by the SEDAC (Socioeconomic Data and Applications Center) project at Columbia University (CIESIN, 2005). This population dataset estimated human population from national and subnational input sources (usually administrative sources) of varying resolutions into regular latitude- longitude grids at the resolution of 2.5 arc-minute grid cells (or $\sim 5 \mathrm{~km}$ at the equator). All population ages $\geq 25$ years is assumed to be exposed because it is not known exactly what proportion of the population is exposed to air pollution at the national level (AIHW, 2010). We used Pe as the proportion of population at ages $\geq 25$ years, which was obtained from Department of Provincial Administration Thailand (Department of Provincial Administration, 2009), and assumed to be constant across the country (Figure 2).

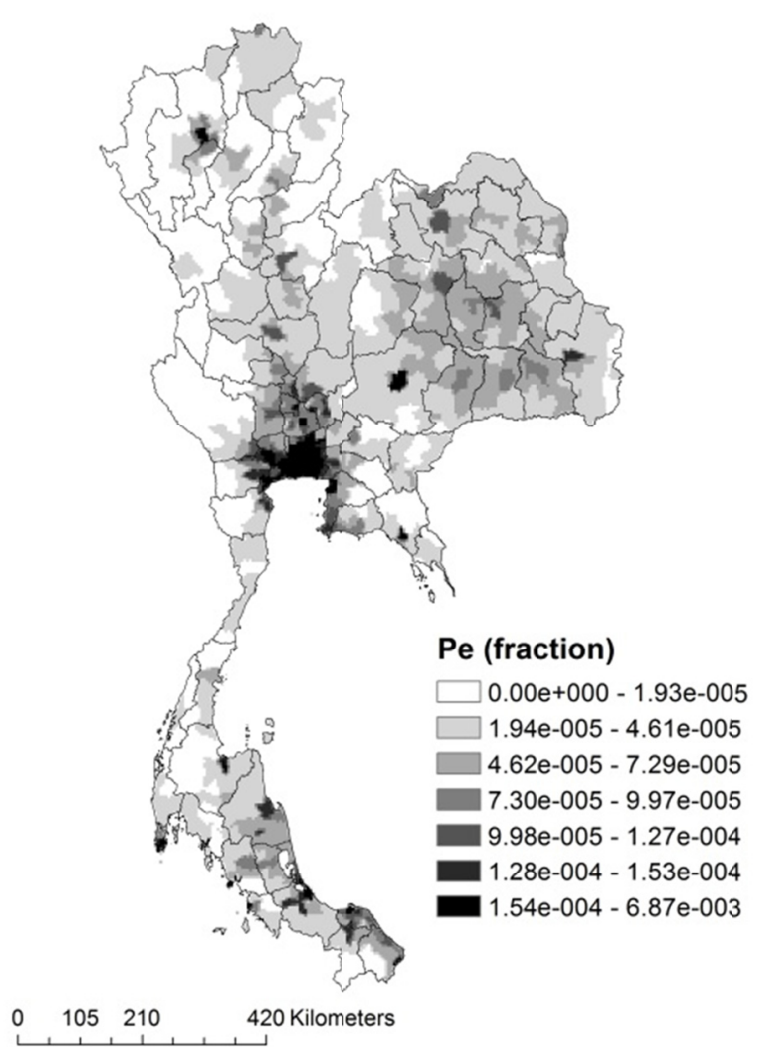

Figure 2. Geographic population distribution of exposure (Pe)

\subsubsection{Estimating Burden Attributable to $\mathrm{O}_{3}$}

To estimate the disease burden attributable to $\mathrm{O}_{3}$, the attributable burden (AB) is multiplied by the total COPD 
disease burden (TB) estimates for the disease and the attributable fraction (PAF). We then estimated the disease burden attributable to $\mathrm{O}_{3}$ according to the formula:

$$
\mathrm{AB}=\mathrm{PAF} \times \mathrm{TB}
$$

$\mathrm{PAF}=$ Proportion of cases that attributed to $\mathrm{O}_{3}$.

$\mathrm{TB}=$ Total COPD disease burden (DALYs).

The total COPD disease burden (DALY) dataset was obtained from BOD Thailand (Thai BOD) (BOD, 2009), which published the national disease burden in Thailand (BOD, 2009). We assumed that the ratio of males to females (sex ratio), is on the same scale as the Thai BOD (Bundhamcharoen, Odton, Phulkerd, \& Tangcharoensathien, 2011).

\section{Results}

We present a number of comparisons of the results using the different spatial modeling described in section 2 . The statistical summary of model performance corresponding to Kriging and IDW interpolation methods are presented in Table 3. Considering the average from the $\mathrm{O}_{3}$ concentrations of 1997 and 2010, the mean predicted $\mathrm{O}_{3}$ concentration of IDW and Kriging in Thailand were: $108.25 \mathrm{ppb}(95 \% \mathrm{CI}, 108.1-108.4)$ and $99.7 \mathrm{ppb}(95 \%$ CI, 99.5-99.8). In this case, IDW was shown to have an approximately $8.6 \%$ larger mean predicted concentration than the Kriging model. Both interpolation models showed that the average $\mathrm{O}_{3}$ concentrations in Thailand exceeded the standard. Furthermore, the IDW model showed the maximum $\mathrm{O}_{3}$ concentration to be approximately $169.6 \mathrm{ppb}$, while the Kriging model gave $131.4 \mathrm{ppb}$, or a $29 \%$ difference. Figure 3 illustrates the cross validation between the measured values at the monitoring stations and the model predictions. For both models, the Pearson correlation of the IDW model $(r=0.272)$ was lower than the Kriging model $(r=0.5)$. In addition, the model performance assessments showed that the MAE and RMSE for $\mathrm{O}_{3}$ varied from 17.9 to 20.25 and 22.58 to 25.13 , respectively. These results revealed that the Kriging interpolation method performed with $10-12 \%$ better accuracy than the IDW method, and clearly indicates that the Kriging provides optimal interpolation model for the exposure assessment based on the empirical dataset in the present study. In addition, the spatial distribution of $\mathrm{O}_{3}$ concentration from the IDW and Kriging model are presented in Figure 4. The Kriging model clearly indicates that the highest $\mathrm{O}_{3}$ concentration levels in the Central and Eastern regions with a range of 117-131 ppb and, the lowest levels in southern region, with a range of 69-83 ppb.

We then calculated $\Delta \mathrm{X}$ in six regions and discovered that the average $\Delta \mathrm{X}$ values were between $64.7-84.9 \mathrm{ppb}$ in Thailand (Table 4). We calculated the summation of PAF grids (Figure 4) by region, as shown in Table 4. Our best PAF estimation indicates that the western region had the lowest PAF value, or about $1.47 \%$ of the total COPD burden. The highest PAF value was located in the central region, which produced $9.6 \%$ of the total COPD burden reflecting the highest $\mathrm{O}_{3}$ concentration levels.

Table 5 summarizes the entire attributable burden due to $\mathrm{O}_{3}$ pollution by region in Thailand. The total burden of disease in Thailand was 10.2 million DALYs, and the estimated total COPD burden in Thailand was 259,512 DALYs (male: 204,312 DALYs; female: 55,199 DALYs) (BOD, 2009). Figure 5 illustrates the distribution of population attributable fractions (PAF) to COPD in Thailand. The Total COPD burden attributable to $\mathrm{O}_{3}$ among six regions was approximately 61,577 DALYs (0.6\% of total DALYs) (male: 48,480 DALYs; female: 13,097 DALYs). The highest attributed $\mathrm{O}_{3}$ burden was clearly located in the central region including the Bangkok Metropolitan Area. The burdens were approximately $9.6 \%$ of the total COPD burden, or about 24,812 DALYs, while the lowest attributed burden was located in the western region, which approximately $1.47 \%$ of total COPD burden, or about 3,804 DALYs. 
Table 3. Statistical summary and model performance parameters of spatial interpolation model

\begin{tabular}{lll}
\hline \multirow{2}{*}{ Statistics measured } & \multicolumn{2}{l}{ Interpolation methods (unit : ppb) } \\
\cline { 2 - 3 } & IDW & Kriging \\
\hline Mean & 108.25 & 99.7 \\
95\% Confidence Interval for Mean & $108.1-108.4$ & $99.5-99.8$ \\
Median & 109.42 & 98.42 \\
Std. Deviation & 12.03 & 14.17 \\
Minimum & 58.94 & 68.84 \\
Maximum & 169.62 & 131.42 \\
Correlation coefficients $(\boldsymbol{P}$-value)) & $0.272(0.051)$ & $0.50 *(0.00)$ \\
MAE & 20.25 & 17.9 \\
RMSE & 25.13 & 22.58
\end{tabular}

Note. * Correlation is significant at the 0.01 level (2-tailed).

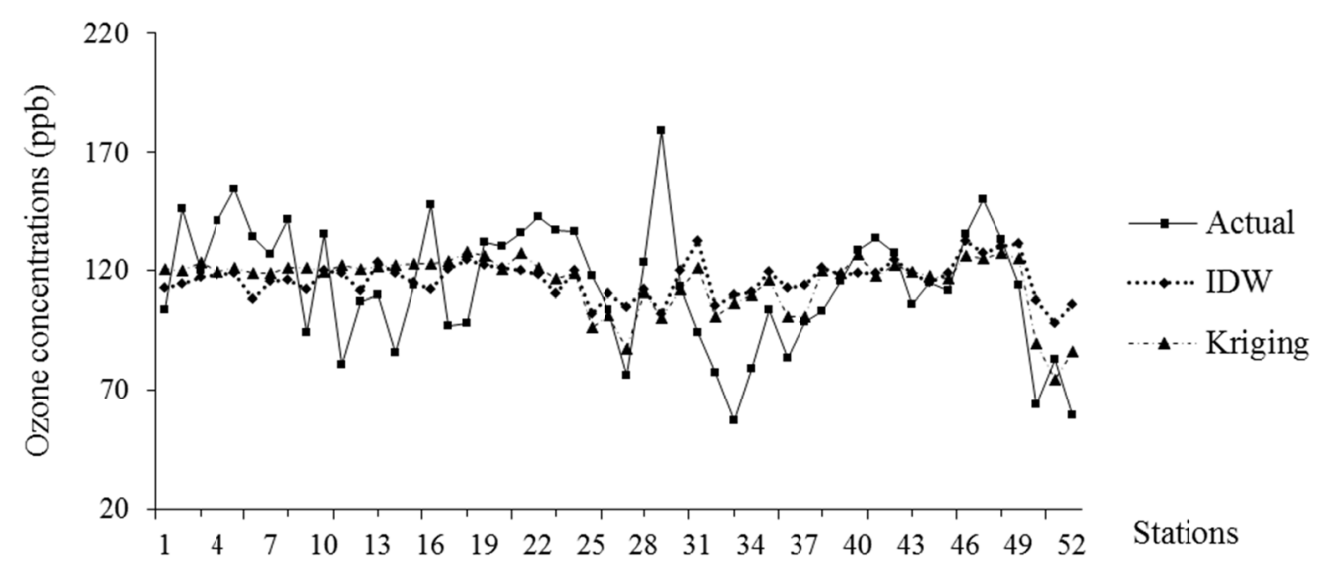

Figure 3. Predicted and actual average daily maximum $\mathrm{O}_{3}$ concentrations (1997-2009) by monitoring stations 

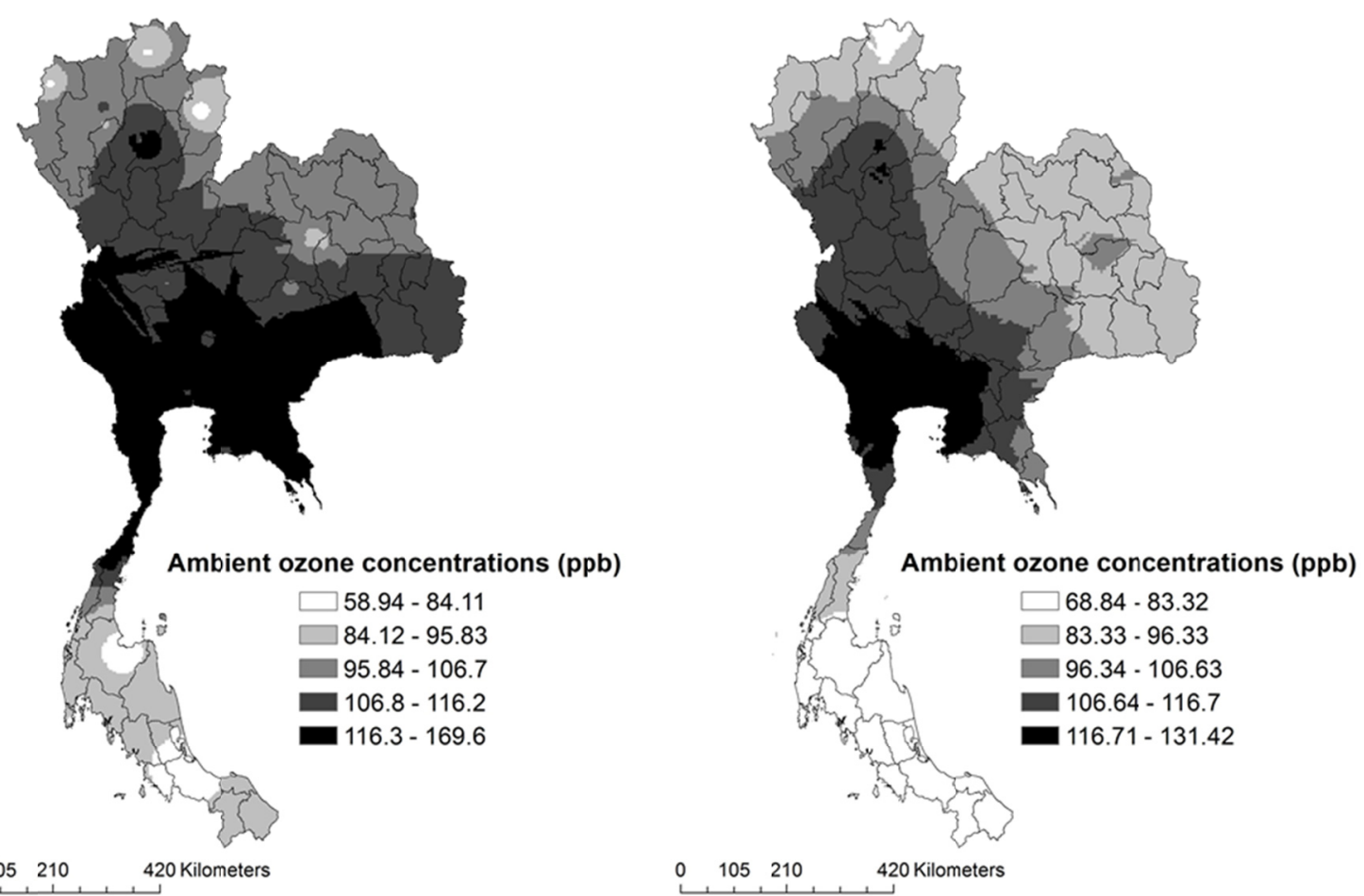

Figure 4. Exposure maps of $\mathrm{O}_{3}$ concentrations in Thailand (2009), IDW (left) and Kriging (right)

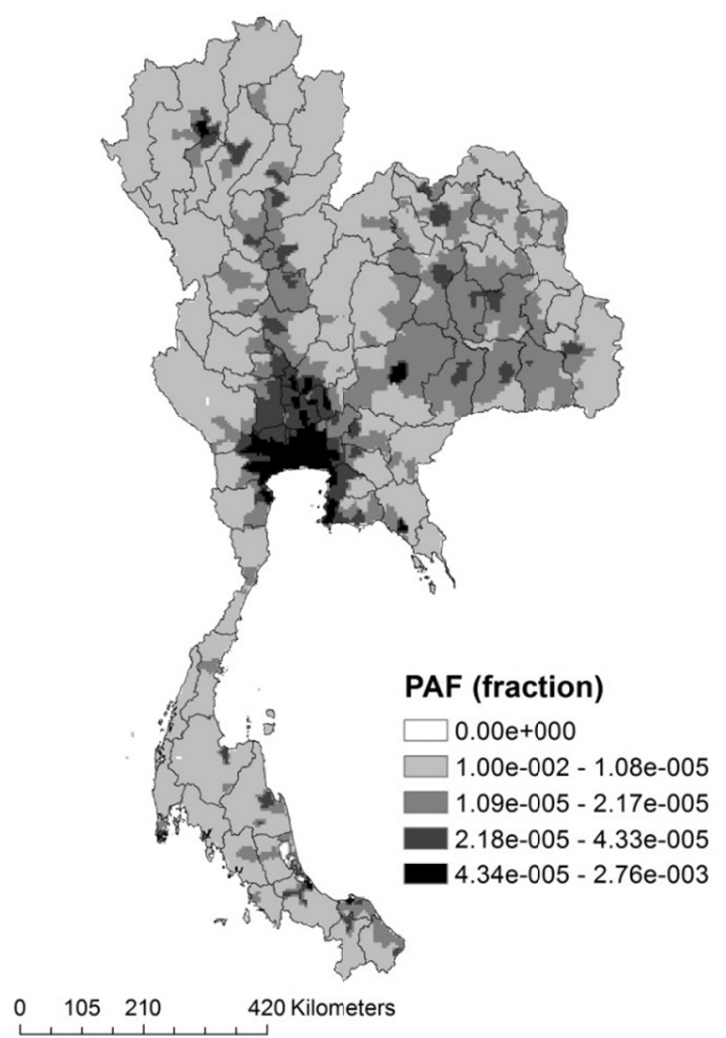

Figure 5. Spatial variation of population attributable fractions (PAF) to COPD in Thailand (2009) 
Table 4. Population $\geq 25$ years, change in concentrations, relative risk and population attributable fractions

\begin{tabular}{|c|c|c|c|c|c|c|c|}
\hline \multirow{2}{*}{ Region } & \multirow{2}{*}{$\begin{array}{l}\text { Pop } \geq 25 \\
\text { (millions) }\end{array}$} & \multicolumn{2}{|l|}{$\Delta \mathbf{x}$} & \multicolumn{2}{|l|}{$\mathbf{R R}$} & \multicolumn{2}{|c|}{$\begin{array}{l}\text { PAF grid } \\
\text { ( } \% \text { of total COPD } \\
\text { DALYs) }\end{array}$} \\
\hline & & Mean & $\begin{array}{l}95 \% \mathrm{CI} \text { for } \\
\text { mean }\end{array}$ & Mean & $\begin{array}{l}95 \% \mathrm{CI} \text { for } \\
\text { mean }\end{array}$ & Mean & $95 \% \mathrm{CI}$ for mean \\
\hline Northern & 3.9 & 64.7 & $57.9-71.4$ & 1.29 & $1.26-1.32$ & 0.0007 & $0.0006-0.0008$ \\
\hline Northeastern & 13.7 & 60.8 & $58.8-62.7$ & 1.27 & $1.26-1.28$ & 0.0014 & $0.0013-0.00143$ \\
\hline Central & 12.7 & 84.9 & $81.8-88.04$ & 1.39 & $1.38-1.41$ & 0.005 & $0.004-0.006$ \\
\hline Eastern & 2.4 & 80.5 & $74-86.9$ & 1.37 & $1.34-1.40$ & 0.0014 & $0.0013-0.0015$ \\
\hline Western & 1.9 & 83.97 & $76.7-91.2$ & 1.39 & $1.35-1.43$ & 0.0008 & 0.0007-0.0009 \\
\hline Southern & 5.2 & 43.5 & $40.4-46.6$ & 1.19 & $1.17-1.20$ & 0.00058 & $0.0005-0.0006$ \\
\hline
\end{tabular}

Table 5. Attributable $\mathrm{O}_{3}$ burden in Thailand

\begin{tabular}{llllll}
\hline \multirow{2}{*}{ Region } & \multicolumn{3}{l}{ Attributable $\mathbf{O}_{\mathbf{3}}$ burden (DALY) } & \multicolumn{2}{c}{ Total DALYs } \\
\cline { 2 - 4 } & Both sexes & Male & Female & (millions) & \% of total DALYs \\
\hline Northern & 5,490 & 4,322 & 1,168 & 1.4 & 0.39 \\
Northeastern & 18,430 & 14,510 & 3,920 & 3.3 & 0.55 \\
Central & 24,813 & 19,535 & 5,278 & 3.0 & 0.83 \\
Eastern & 4,531 & 3,567 & 963 & 0.7 & 0.69 \\
Western & 3,804 & 2,995 & 809 & 0.5 & 0.77 \\
Southern & 4,510 & 3,551 & 959 & 1.3 & 0.35 \\
Total & 61,577 & 48,480 & 13,097 & 10.2 & 0.60 \\
\hline
\end{tabular}

\section{Discussion}

This study estimated the health burden of diseases due to $\mathrm{O}_{3}$, using GIS interpolation models and health impact function, and followed the comparative risk assessment method (CRA) from the global burden of disease (GBD) study. This approach makes it possible to assess the burden attributable to empirical data sources for $\mathrm{O}_{3}$ exposure, e.g., surface monitor measurements, while taking into consideration the population exposure at the national level. Our results indicate that the burden of disease attributable to $\mathrm{O}_{3}$ is approximately 61,577 DALYs $(0.6 \%$ of total DALYs) (male: 48,480 DALYs; female: 13,097 DALYs). The only source of relative risks due to $\mathrm{O}_{3}$ from the GBD study is Jerrett et al. (2009), a major cohort study in the United States and also the first study to show significant $\mathrm{O}_{3}$ exposure long-term health impacts.

We estimated $\mathrm{O}_{3}$ exposure by two spatial exposure-modeling techniques, i.e., IDW and Kriging. The cross-validation technique was used to test the model accuracy from the air pollution exposure study (Thepanondh \& Toruksa, 2011), because it does not require additional data collection from areas without an air surface monitoring station. It removes a known point from the interpolated dataset and the residual dataset is used to evaluate the prediction at the known point that it had been removed. The model performance indicator of each of the interpolation methods is shown in Table 4, and the predicted cross-validation data is shown in Figure 2. Both interpolation techniques were useful for estimating the exposure from the unknown areas, but the results showed that the Kriging, which produced smaller RMSE and MAE values, performed better than IDW. Using the Kriging method as shown in Figure 4, an $\mathrm{O}_{3}$ concentration exposure map from spatial distributed interpolation was produced.

From our study, the average $\Delta \mathrm{X}$ value in Thailand $=69.3 \mathrm{ppb}(95 \% \mathrm{CI}$ 62-70). These figures are larger than Horowitz's simulation at 10-25 ppb (Horowitz, 2006); Horowitz used the chemistry transport model to generate globally simulated $\mathrm{O}_{3}$ concentrations of $30-50 \mathrm{ppb}$ in area of Thailand. To improve these results at the national level, increasing the number and distribution of monitoring stations is required in the future because of a lack of representative surface monitored data in some high population provinces (populations $>1$ million) in Thailand. 
For example, Ubon ratchathani, Udon Thani and Buriram in northeastern region, Nakhon Si Thammarat in southern region, all high population provinces, lack representative surface monitored data.

Figure 4 illustrates how the population attributable fraction due to $\mathrm{O}_{3}$ exposure varies across Thailand. The population attributable fraction was the highest in the Central region (including Bangkok Metropolitan Area), most likely because the higher population distribution of exposure (figure 2) and $\mathrm{O}_{3}$ concentrations levels (figure 4) are located in this region. Furthermore, we found that the spatial variation of population attributable fractions were generally more consistent with the population distribution of exposure than the $\mathrm{O}_{3}$ concentrations, similar to the previous study that suggested the exposure comes with population; no population, no exposure (Hao, Flowers, Monti, \& Qualters, 2012). The highest attributable COPD burden due to $\mathrm{O}_{3}$ was located in Central region, or about 24,812 DALYs. This may be due to the population distribution of exposure and pollution levels, but also because the total COPD DALY in the Central region was consistently high as well. However, the Northern region, which had the highest COPD DALY in Thailand, had lower estimated $\mathrm{O}_{3}$ attributable disease burden than the Central region (5,490 DALYs). This may be because the $\mathrm{O}_{3}$ concentrations were slightly lower (64.7 ppb, 95\% CI; 57.9-71.4) than the Central region (84.9 ppb, 95\% CI; 81.8-88.04), the population distribution of exposure was relatively smaller than the Central region, and the major sources of air pollution which are associated with COPD in the Northern region may differ from the Central region (e.g. forest fire, and garbage burnings)(Sukitpaneenit \& Kim Oanh, 2014; Wiwatanadate, 2014).

In a previous study, GBD 2010 ( $\mathrm{Lim}$ et al., 2012), estimated the disease burden attributable to $\mathrm{O}_{3}$ to be approximately $0.1 \%$ of the global DALYs $(152,434$ deaths: both sex) in 2010, our best estimate, however, is $0.45-1 \%$, depending on the province/region, or a total of 61,577 DALYs $(0.6 \%$ of the total national disease burden). Our results indicate that our PAFs were slightly greater than the GBD study. One explanation may be that the exposure estimation method. GBD used the global chemistry transport models (Fiore, Dentener, Wild, Cuvelier, \& Schultz, 2009; Stevenson et al., 2006) to estimate the distribution of $\mathrm{O}_{3}$. GBD did not link the available surface monitor data and statistical model to estimate exposure distribution similar to the fine particulate matter (PM2.5) in their study, which reflects a lack of available local empirical data. In addition, the estimations for the $\mathrm{O}_{3}$ disease burden in Thailand are approximate to the United Arab Emirates (UAE). Based on the air quality monitoring stations in the UAE, and the spatial exposure modeling technique, Ying $\mathrm{Li}$ et al. ( $\mathrm{Li}$ et al., 2010) estimated that disease attributed to ground-level $\mathrm{O}_{3}$ exposure in UAE was approximately $0.8 \%(95 \%$ CI; $0.2-2 \%$ ) of the total UAE disease burden in 2007.

We note that our study has some inherent limitations, which need to be addressed. We rely on $\mathrm{O}_{3}$ pollution data from existing monitoring stations network. In addition, the exposure assessment based on the surface monitoring measurements may vary, depending on location, air quality monitoring stations density and seasonal variation in $\mathrm{O}_{3}$ pollution which may not be uniformly distributed across Thailand. For that reason, it is possible that our model was overestimates to simulate annual $\mathrm{O}_{3}$ exposure into large scale area (e.g. national scale). We recommend that future research should consider another ambient air quality model to simulate $\mathrm{O}_{3}$ concentrations, e.g. land use regression (Ryan \& LeMasters, 2007) and photochemical modeling (Fann et al., 2012) to more accurately assess $\mathrm{O}_{3}$ pollution and population exposure on a national scale.

In the study limitation, we assumed that the exposure was equal for all members of the population $\geq 25$ years (AIHW, 2010). For that reason, it should be noted that using an urban/local area-weighting method to estimate population exposure (Zhang, Qi, Jiang, Zhou, \& Wang, 2013) due to $\mathrm{O}_{3}$, and the higher resolution population dataset at a resolution of 30 arc-seconds $(\sim 1 \mathrm{~km})$, which allocating census block population and household information into regular latitude longitude grids (Balk et al., 2006), are required to improve the contribution on the Pe factor at the local level.

Another limitation is that our study relies on the health outcome model from the GBD study (Lim et al., 2012), and also concentration-response coefficients (CR) from an epidemiological study (M. Jerrett et al., 2009) despite differences in health status, lifestyle, age structure, and medical care (Anenberg et al., 2010). Therefore, we did not account for short-term effects by the ambient $\mathrm{O}_{3}$ pollution, which is related to cardiovascular and respiratory mortality (e.g. Bell et al., 2004). These limitations may be eliminated in future research if local epidemiological studies are available.

\section{Conclusion}

Our study aims to estimate the disease burden attributed to ozone in Thailand. This study presents an integrated exposure assessment, using a spatial interpolation model from empirical data, population distribution exposure and health impact function to estimate national disease burden attributable to $\mathrm{O}_{3}$. Our study indicated that ambient $\mathrm{O}_{3}$ is one of the major air pollutants that exerts adverse effects on the environment and human health in 
Thailand. The estimated COPD burden cause by $\mathrm{O}_{3}$ in our study was about $0.6 \%$ of the national burden each year. It is our hope that the results will initiate more precise $\mathrm{O}_{3}$ and/or other air pollution health burden estimations among scientists in future environmental health burden studies. Finally, this study provides the first national estimate and can inform decision-making by stakeholders and policy-makers to promote and manage a health co-benefit of green economy in the future.

\section{Acknowledgements}

This study is a part of the National Burden of Disease program, supported by the Thai Health Promotion Foundation and the National Health Security Office. We are grateful to the Air Quality and Noise Management Bureau, Pollution Control Department Thailand for providing the $\mathrm{O}_{3}$ data from the background monitoring stations. We especially thank Candyce Silva, International Health Policy Program, Thailand for her excellent English proofreading.

\section{References}

AIHW. (2010). Monitoring the impact of air pollution on asthma in Australia.

Anenberg, S. C., Horowitz, L. W., Tong, D. Q., \& West, J. J. (2010). An estimate of the global burden of anthropogenic ozone and fine particulate matter on premature human mortality using atmospheric modeling. Environ Health Perspect, 118(9), 1189-1195. http://dx.doi.org/10.1289/ehp.0901220

Balk, D. L., Deichmann, U., Yetman, G., Pozzi, F., Hay, S. I., \& Nelson, A. (2006). Determining Global Population Distribution: Methods, Applications and Data. Advances in Parasitology, 62, 119-156. http://dx.doi.org/10.1016/S0065-308X(05)62004-0

Bell, M. L., McDermott, A., Zeger, S. L., Samet, J. M., \& Dominici, F. (2004). Ozone and short-term mortality in 95 US urban communities, 1987-2000. Jama, 292(19), 2372-2378. http://dx.doi.org/10.1001/jama.292.19.2372

BOD, T. (2009). The burden of disease and injury of the population in Thailand.

Bundhamcharoen, K., Odton, P., Phulkerd, S., \& Tangcharoensathien, V. (2011). Burden of disease in Thailand: changes in health gap between 1999 and 2004. [Research Support, Non-U S Gov't]. BMC Public Health, 11(53), 1471-2458. http://dx.doi.org/10.1186/1471-2458-11-53.

CIESIN. (2005). Gridded Population of the World, Version 3 (GPWv3): Population Density Grid (Publication no. http://dx.doi.org/10.7927/H4XK8CG2). Retrieved 20150305, from NASA Socioeconomic Data and Applications Center (SEDAC) http://dx.doi.org/10.7927/H4XK8CG2

Denby, B., Sundvor, I., Cassiani, M., de Smet, P., de Leeuw, F., \& Horálek, J. (2010). Spatial Mapping of Ozone and SO2 Trends in Europe. Science of The Total Environment, 408(20), 4795-4806. http://dx.doi.org/10.1016/j.scitotenv.2010.06.021

Department of Provincial Administration, T. (2009). Official Statistics Registration Systems. Retrieved from http://stat.bora.dopa.go.th/stat/

Dilip Kumar Jha, Sabesan, M., Anup Das, Vinithkumar, N. V., \& Kirubagaran, R. (2011). Evaluation of Interpolation Technique for Air Quality Parameters in Port Blair, India.

Fann, N., Lamson, A. D., Anenberg, S. C., Wesson, K., Risley, D., \& Hubbell, B. J. (2012). Estimating the national public health burden associated with exposure to ambient PM2.5 and ozone. Risk Anal, 32(1), 81-95. http://dx.doi.org/10.1111/j.1539-6924.2011.01630.x

Fiore, A. M., Dentener, F. J., Wild, O., Cuvelier, C., \& Schultz, M. G. (2009). Multimodel estimates of intercontinental source-receptor relationships for ozone pollution. Journal of Geophysical Research: Atmospheres, 114(D4), n/a-n/a. http://dx.doi.org/10.1029/2008JD010816

Gorai, A. K., Tuluri, F., \& Tchounwou, P. B. (2014). A GIS Based Approach for Assessing the Association between Air Pollution and Asthma in New York State, USA. International Journal of Environmental Research and Public Health, 11(5), 4845-4869. http://dx.doi.org/10.3390/ijerph110504845

Hao, Y., Flowers, H., Monti, M. M., \& Qualters, J. R. (2012). U.S. census unit population exposures to ambient air pollutants. Int J Health Geogr, 11(3), 11-13. http://dx.doi.org/10.1186/1476-072X-11-3

Horowitz, L. W. (2006). Past, present, and future concentrations of tropospheric ozone and aerosols: methodology, ozone evaluation, and sensitivity to aerosol wet removal. J. Geophys. Res., 111 . http://dx.doi.org/10.1029/2005JD006937. 
Huang, Y., Dominici, F., \& Bell, M. L. (2005). Bayesian hierarchical distributed lag models for summer ozone exposure and cardio-respiratory mortality. Environmetrics, 16(5), 547-562. http://dx.doi.org/10.1002/env.721

Hunova, J. H., Schreiberova, M., \& Zapletal, M. (2011). Ambient Ozone Exposure in Czech Forests: A GIS-Based Approach to Spatial Distribution Assessment. The ScientificWorld Journal, 2012, 1-10. http://dx.doi.org/10.1100/2012/123760

Ito, K., Thurston, G. D., \& Silverman, R. A. (2007). Characterization of PM2.5, gaseous pollutants, and meteorological interactions in the context of time-series health effects models. $J$ Expo Sci Environ Epidemiol, 17(2), 7500627. http://dx.doi.org/10.1038/sj.jes.7500627

Janssen, S., Dumont, G., Fierens, F., \& Mensink, C. (2008). Spatial interpolation of air pollution measurements using CORINE land cover data. Atmospheric Environment, 42(20), 4884-4903. http://dx.doi.org/10.1016/j.atmosenv.2008.02.043

Jerrett, M., Burnett, R. T., Beckerman, B. S., Turner, M. C., Krewski, D., Thurston, G., . . Pope, C. A. (2013). Spatial Analysis of Air Pollution and Mortality in California. American Journal of Respiratory and Critical Care Medicine, 188(5), 593-599. http://dx.doi.org/10.1164/rccm.201303-0609OC

Jerrett, M., Burnett, R. T., Pope, C. A., 3rd, Ito, K., Thurston, G., Krewski, D., . . Thun, M. (2009). Long-term ozone exposure and mortality. [Research Support, Non-U.S. Gov't]. N Engl J Med, 360(11), 1085-1095. http://dx.doi.org/10.1056/NEJMoa0803894

Kethireddy, S. R., Tchounwou, P. B., Ahmad, H. A., Yerramilli, A., \& Young, J. H. (2014). Geospatial Interpolation and Mapping of Tropospheric Ozone Pollution Using Geostatistics. International Journal of Environmental Research and Public Health, 11(1), 983-1000. http://dx.doi.org/10.3390/ijerph110100983

Levin, M. L. (1953). The occurrence of lung cancer in man. Acta Unio Int Contra Cancrum, 9(3), 531-541.

Li, Y., Gibson, J. M., Jat, P., Puggioni, G., Hasan, M., West, J. J., . . Serre, M. (2010). Burden of disease attributed to anthropogenic air pollution in the United Arab Emirates: estimates based on observed air quality data. [Research Support, Non-U S Gov't]. Sci Total Environ, 408(23), 5784-5793. http://dx.doi.org/10.1016/j.scitotenv.2010.08.017

Lim, S. S., Vos, T., Flaxman, A. D., Danaei, G., Shibuya, K., \& Adair-Rohani, H. (2012). A comparative risk assessment of burden of disease and injury attributable to 67 risk factors and risk factor clusters in 21 regions, 1990-2010: a systematic analysis for the Global Burden of Disease Study 2010. Lancet, 380(9859), 2224-2260. http://dx.doi.org/10.1016/S0140-6736(12)61766-8

Moral García, F. J., P. V. G., \& López Rodríguez, F. (2010). Geostatistical Analysis and Mapping of Groundlevel Ozone in a Medium Sized Urban Area. International Journal of Civil and Environmental Engineering, 2(2), $72-82$.

Murray, C. J. (1994). Quantifying the burden of disease: the technical basis for disability-adjusted life years. Bull World Health Organ, 72(3), 429-445.

Murray, C. J., Ezzati, M., Lopez, A. D., Rodgers, A., \& Vander Hoorn, S. (2003). Comparative quantification of health risks conceptual framework and methodological issues. Popul Health Metr, 1(1), 1. http://dx.doi.org/10.1186/1478-7954-1-1

Nuckols, J. R., \& Lars Jarup. M. H. W. (2004). Using Geographic Information Systems for Exposure Assessment in Environmental Epidemiology Studies. Environ Health Perspect, 112(9), 1007-1015. http://dx.doi.org/10.1289/ehp.6738

Pollution Control Department, T. (2007). Overview of Air Quality Management in Thailand.

Roberts, J. D., Voss, J. D., \& Knight, B. (2014). The Association of Ambient Air Pollution and Physical Inactivity in the United States. PLoS One, 9(3), e90143. http://dx.doi.org/10.1371/journal.pone.0090143

Rockhill, B., Newman, B., \& Weinberg, C. (1998). Use and misuse of population attributable fractions. Am $J$ Public Health, 88(1), 15-19.

Ruchirawat, M., Settachan, D., Navasumrit, P., Tuntawiroon, J., \& Autrup, H. (2007). Assessment of potential cancer risk in children exposed to urban air pollution in Bangkok, Thailand. Toxicology Letters, 168(3), 200-209. http://dx.doi.org/10.1016/j.toxlet.2006.09.013

Ryan, P. H., \& LeMasters, G. K. (2007). A Review of Land-use Regression Models for Characterizing Intraurban 
Air Pollution Exposure. Inhalation toxicology, $19(\mathrm{Suppl} \quad 1), \quad$ 127-133. http://dx.doi.org/10.1080/08958370701495998

Stevenson, D. S., Dentener, F. J., Schultz, M. G., Ellingsen, K., van Noije, T. P. C., Wild, O., . . Szopa, S. (2006). Multimodel ensemble simulations of present-day and near-future tropospheric ozone. Journal of Geophysical Research: Atmospheres, 111(D8), n/a-n/a. http://dx.doi.org/10.1029/2005jd006338

Sukitpaneenit, M., \& Kim Oanh, N. T. (2014). Satellite monitoring for carbon monoxide and particulate matter during forest fire episodes in Northern Thailand. Environ Monit Assess, 186(4), 2495-2504.

Thanh, B. D., \& Lefevre, T. (2000). Assessing health impacts of air pollution from electricity generation: the case of Thailand. Environmental Impact Assessment Review, 20(2), 137-158. http://dx.doi.org/10.1016/S0195-9255(99)00041-4

Thepanondh, S., \& Toruksa, W. (2011). Proximity analysis of air pollution exposure and its potential risk. [Research Support, Non-U.S. Gov't]. $J$ Environ Monit, 13(5), 1264-1270. http://dx.doi.org/10.1039/c0em00486c

Verónica, V. (2013). Assessing the Spatial Distribution of Perfluorooctanoic Acid Exposure via Public Drinking Water Pipes Using Geographic Information Systems. Environmental Health and Toxicology, 28, 1-5. http://dx.doi.org/10.5620/eht.2013.28.e2013009

WHO. (2004). Comparative Quantification of Health Risks - Global and regional burden of disease attributable to selected major risk factors. A. D. L. Majid Ezzati, Anthony Rodgers and Christopher J. L. Murray (Ed.). Retrieved from www.who.int/publications/cra.

WHO. (2011). Global burden of diseases. Retrieved from http://www.who.int/healthinfo/global_burden_disease/en/

Wiwatanadate, P. (2014). Acute air pollution-related symptoms among residents in Chiang Mai, Thailand. [Research Support, Non-U S Gov't]. J Environ Health, 76(6), 76-84.

Wong, D. W., Yuan, L., \& Perlin, S. A. (2004). Comparison of spatial interpolation methods for the estimation of air quality data. [Comparative Study]. J Expo Anal Environ Epidemiol, 14(5), 404-415. http://dx.doi.org/10.1038/sj.jea.7500338

Zhang, A., Qi, Q., Jiang, L., Zhou, F., \& Wang, J. (2013). Population exposure to PM2.5 in the urban area of Beijing. [Research Support, Non-U S Gov't]. PLoS One, 8(5). http://dx.doi.org/10.1371/journal.pone.0063486

\section{Copyrights}

Copyright for this article is retained by the author(s), with first publication rights granted to the journal.

This is an open-access article distributed under the terms and conditions of the Creative Commons Attribution license (http://creativecommons.org/licenses/by/3.0/). 